\title{
Framework welcome, but could do with fine-tuning
}

\section{Let's get details sorted out, timescales defined, postdocs funded, entrepreneurs trained.}

Sir - The European Commission proposal for the sixth Framework programme (FP6) needs to be adopted before December to avoid a break in European research programmes. Several key elements of the proposal deserve strong support, such as networking national programmes; increased coherence of national science and technology policies; increased mobility for researchers; and the longrequested simplification of project management via a decentralized system. And of course, we can only applaud the proposed significant increase in the overall budget for European science and technology research.

Nevertheless, as stated in the Opinion article "Storm clouds over Brussels" (Nature 411,871; 2001), important aspects of the proposal need to be clarified, and the details of how the objectives are to be put into action have not been properly addressed.

Previous Framework programmes have been beneficial, but have had recurring, still unsolved, administrative problems. Although the FP6 proposals should provide better flexibility and efficiency, it remains to be explained how the projects will actually be managed. Clear timescales for reviewing applications and delivering money should be defined at the outset.

The current Framework system does not provide funding mechanisms or coordinating bodies for Europe-wide basic and strategic science. Your Opinion article suggested as one candidate the coal and steel research fund. The European Science Foundation's Eurocores programme is another, in which case FP6 should contribute to its funding.

Although FP6 provides strong support for the mobility of researchers in the European Union, several categories of scientists remain unable to benefit from this money, including doctoral students. Postgraduate students should be allowed to benefit from this money as they are the key to better collaboration between universities and greater compatibility between doctoral programmes in different European countries. Longer-term funding to help postdocs find their first tenured position should also be made available, as proposed by the Marie Curie Fellowship Association. In addition, the provision of return grants should be developed, to help young European scientists (especially those from Eastern Europe) return to their home countries with decent support.

Feasibility studies, as well as the initial investment and, in some cases, operating costs of novel research infrastructures, should be funded by the Framework programme. A high-level coordinating body is necessary to ensure the continuity and coherence of policy decision in this domain. International collaboration also appears to be poorly provided for; collaborations with Mediterranean and developing countries in particular are greatly underfunded.

Finally, European start-up companies suffer from the insufficient training of

\section{Climate-change strategy needs to be robust}

Sir - Stephen Schneider argues in his Commentary "What is 'dangerous' climate change?" (Nature 411, 17-19; 2001) that the Intergovernmental Panel on Climate Change should assign subjective probabilities to the "storyline" scenarios of future climate change offered in its recent special report on emissions scenarios (SRES), because probabilities will be required by policy-makers.

Schneider raises an important concern, in that a set of plausible scenarios does not, by itself, tell policy-makers what is likely to happen or provide clear guidance for action. But his proposal does not take into account that decision-makers must form a climate policy acceptable to groups with many different, yet plausible, estimates of the likelihood of alternative futures.

This condition of deep uncertainty differs from many risk-management problems, in that little solid information exists to inform subjective probabilities for the long-term economic, social and technological trends underlying different greenhouse-gas emission scenarios. It is unlikely that scientific evidence will soon resolve the assumptions about the socio-economic future made by different groups.

Under such conditions of deep uncertainty, decision-makers often rely on robustness - that is, strategies that work reasonably well compared with the alternatives across a wide range of plausible scenarios (R. J. Lempert \& M. E. Schlesinger, Climatic Change 45, 387-401; 2000). They then form a policy solution that works reasonably well for all possibilities. In contrast, an optimum strategy requires probabilities for alternative scenarios, which can invite discord, as well as leading to policies that would-be entrepreneurs in capital fundraising compared with their US counterparts. Training in venture-capital rules should be co-funded by FP6 to help European business innovation. In addition, a European insurance body should be set up to cover the costs of patenting and of defending patents at the international level.

\section{Frédéric Sgard}

Euroscience, Sanofi-Synthélabo, 10 Rue des Carrières, 92500 Rueil-Malmaison, France can fail in some plausible futures.

In our view, the SRES team was correct to avoid assigning probabilities and instead recommend use of ensembles of multiple scenarios to capture what is known about the long-term climate future. Researchers can now use such scenarios to assess the robustness of alternative, near-term climate policies. Such studies are likely to suggest near-term policy choices that are largely insensitive to many uncertainties. Only when such studies also reveal a few key assumptions to which near-term choices are particularly sensitive, can scientists take the perilous step of putting limits on the range of subjective probabilities for those few assumptions. Robert Lempert $^{\star}$, Michael E. Schlesinger $\dagger$ ${ }^{*}$ RAND, 1700 Main Street, Santa Monica, California 90407-2138, USA

†Department of Atmospheric Sciences, University of Illinois at Urbana-Champaign, 105 S. Gregory Street, Urbana, Illinois 61801-3070, USA

\section{When three's not a crowd}

Sir - You are showing your zoocentric side with your description on the In This Issue page of the rarity of three-way symbioses ("Ménage a trois", Nature 411, $\mathrm{xi}$; 2001). This sort of arrangement is not so rare among plants: for example, leguminous plants with mycorrhizal associations - see Lichen Biology (ed. T. Nash III, Cambridge Univ. Press, 1996). An even more intimate relationship exists among a number of tripartite lichens, where a composite organism is formed through the symbiosis of an ascomycete, a chlorophytic alga and a cyanobacterium. This association can be so specific that, from a practical standpoint, at least two of the individual partners may not exist outside the symbiotic relationship. Michael A. Thomas

Department of Biochemistry, University of Otago, PO Box 56, Dunedin 9015, New Zealand 